Reprinted from Gill, C., Barrio, C , \& Myers, J. E., (2010). Spirituality and Religiosity: Factors Affecting Wellness Among Low Income Rural Women. Journal of Counseling \& Development. 88, 293-302. The American Counseling Association. Reprinted with permission.

No further reproduction authorized without written permission from the American Counseling Association: http://www.counseling.org/

\title{
Spirituality and Religiosity: Factors Affecting Wellness Among Low-Income, Rural Women
}

\author{
Carman S. Gill, Casey A. Barrio Minton, and Jane E. Myers
}

A study including measures of spirituality, religiosity, and wellness was conducted to identify coping strategies for the multiple challenges to wellness faced by low-income, rural women. Total spirituality and religiosity accounted for $39 \%$ of the variance in wellness, with purpose and meaning in life, unifying interconnectedness, and private religious practices composing the main contributions. Implications for counselors working with these women are discussed, as is the need for further research.

Women compose more than half of all individuals living in poverty in the United States (U.S. Department of Agriculture [USDA], n.d.). In rural communities, where poverty rates are higher than in the general population, more than 3.75 million women, living alone or as heads of households, are poor (USDA, n.d.). These women experience challenges concomitant with rural poverty, including multiple risk factors for physical and mental health related to economic (United Nations, 1995; Wilson \& Peterson, 1993), social (Amato \& Zuo, 1992; Haynie \& Gorman, 1999), familial (Amato \& Zuo, 1992), and individual (Reutter, Neufield, \& Harrison, 2001) circumstances. Myers and Gill (2004) presented the Cycle of Poverty and Compromised Wellness "as a conceptual framework for understanding the mental health needs of young, rural, poor females" (p. 235) in response to these important and pervasive life challenges. They also suggested that counselors could use this model to provide effective, strength-based interventions to help rural women develop more positive lifestyles.

An examination of the Cycle of Poverty and Compromised Wellness (Myers \& Gill, 2004; see Figure 1) reveals a complex, negative cycle of interacting factors. Not shown in the model, however, are strategies for interrupting this cycle and promoting positive lifestyle choices. For example, although both spirituality and religiosity have been established as coping mechanisms for stressful life circumstances for people in general (Koenig \& Larson, 2001), few studies of these factors among rural populations have been conducted. A notable exception was Barusch's (1999) study of older, low-income women, in which a link between religion, adversity, and well-being was established for some of the study participants. England and Finch (1991) identified religious beliefs and behaviors as being particularly important for rural and midlife women; however, their sample was small and not representative of the general population. The results of these studies suggest that both spirituality and religiosity may affect wellness among poor, rural women. Nevertheless, the relationship between these factors and holistic wellness has not been examined.

The present study was undertaken to explore the relationships among spirituality, religiosity, and wellness for lowincome, rural women. The following research questions were addressed: (a) What are the relationships among spirituality, religiosity, and wellness for low-income, rural women? (b) Are there differences in spirituality, religiosity, or wellness among subgroups of this population on the basis of race/ethnicity? (c) What percentage of variance in wellness can be accounted for by spirituality and religiosity? and (d) What specific components of spirituality and religiosity predict wellness? Before exploring these questions, we provide a brief review of the literature for each variable, including definitions that are important for understanding the relationships among the variables as well as implications for counseling.

\section{Spirituality}

Cashwell and Young (2005) observed that spirituality is difficult to define, given that it is both universal (e.g., $96 \%$ of the American population report a belief in God) and highly personal. Numerous authors from faith traditions as well as psychological sciences have attempted definitions, in many cases as the foundation for assessment of multidimensional spiritual concepts such as spiritual wellness. For example, Myers (1990) defined spiritual wellness as "a continuing search for purpose and meaning in life; an appreciation for depth of life, the expanse of the universe, and natural forces which operate; a personal belief system" (p. 11). Myers and Sweeney (2005a) defined spirituality as "an awareness of a being or force that transcends the material aspects of life and gives a deep sense of wholeness or connectedness to the universe" (p. 20). Moberg and Brusek (1978) included inner resources, meaning-giving center, and concerns and values of individuals as components 


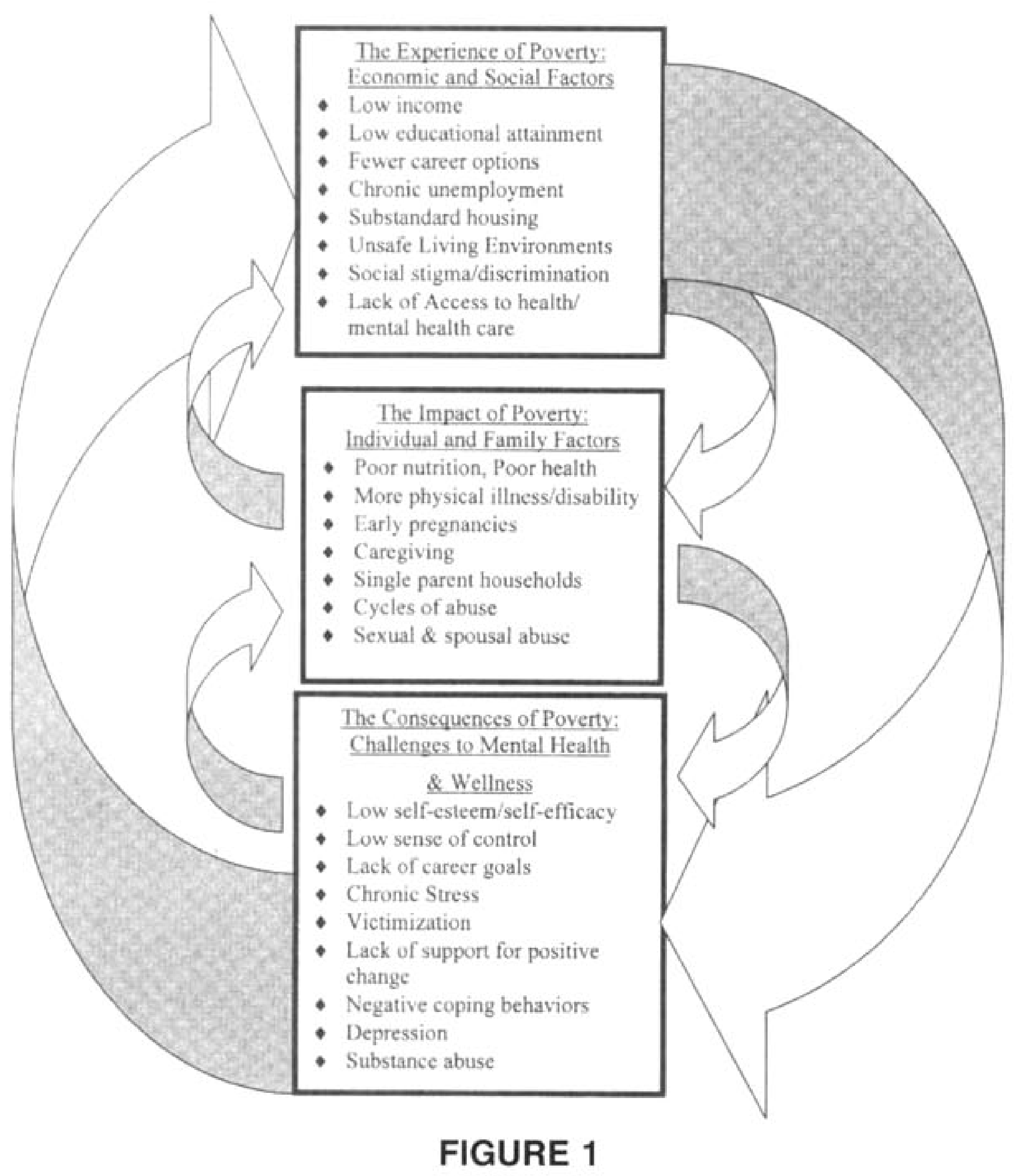

The Cycle of Poverty and Compromised Wellness

Note. Adapted from "The World Health Report 2001: Mental Health: New Understanding, New Hope" (p.14), by World Health Organization, 2001, Geneva, Switzerland: World Health Organization. Copyright 2001 by the World Health Organization. Adapted with permission. Adapted version originally printed in "Poor, Rural and Female: Under-Studied, Under-Counseled, More At-Risk," by J. E. Myers and C. S. Gill, 2004, Journal of Mental Health Counseling, 26, p. 231.

of spiritual well-being. Chandler, Holden, and Kolander (1992) described spiritual wellness as "a balanced openness to or pursuit of spiritual development" (p. 169).

Westgate (1996) defined spiritual wellness in terms of four major themes: purpose and meaning in life, intrinsic values, transcendence, and community of shared values. She noted that meaning and purpose in life were recognized by most existentialists and counseling theorists as central to spiritual wellness and strongly associated with self-actualization. Having "an intrinsically held value system that forms the basis of one's behavior" (Westgate, 1996, p. 29) contributes to a sense of well-being, and persons who consider themselves to be part of a larger plan and find wonder in the universe realize transcendence. A spiritual community provides individuals with a method for expressing spiritual values, mutual support of spirituality, and a platform for service to other community members and the larger community. Although not fully tested empirically, Westgate's Spiritual Wellness model builds on existing literature that underscores the pervasive, positive effect of spiritual beliefs and practices, particularly regarding coping behaviors.
Lindgren and Coursey (1995) reviewed studies on spirituality and coping and concluded that spirituality buffers stressful life events. In other studies, spirituality has been found to be strongly correlated with positive health (Seaward, 1995) and has been shown to improve holistic well-being (Koenig, 1991). For a variety of disenfranchised groups, components of spirituality have been identified as helpful in coping with major life challenges (Holt, Clark, Kreuter, \& Rubio, 2003; Mendelson, 2002). Spirituality has been shown to be an effective means of coping for women recovering from breast cancer (Ashing, Padilla, Tejero, \& Kagawa-Singer, 2003), dealing with the death of children (Brotherson \& Soderquist, 2002), recovering from substance abuse (Brome, Owens, Allen, \& Vevaina, 2000), leaving battering relationships (Dunbar \& Jeannechild, 1996), and surviving childhood sexual abuse (Dabney, 2000). Although there is no distinction made in many of these studies, several authors have suggested the importance of discriminating between the separate concepts of spirituality and religiosity (Cashwell \& Young, 2005; Hackney \& Sanders, 2003; Miller, 1999). 


\section{Religiosity}

As is true of spirituality, religiosity is a difficult term to define (Fetzer Institute, 1999; Hackney \& Sanders, 2003), resulting in many definitions and models (Hill \& Pargament, 2003). Nevertheless, most theorists agree that religiosity differs from spirituality (Fetzer Institute, 1999; Miller, 1999), describing religiosity as the external or outward expression of the inward spiritual system (Elkins, Hedstrom, Hughes, Leaf, \& Saunders, 1988; Myers, Sweeney, \& Witmer, 2000; Westgate, 1996). Multifaceted models of religiosity, such as Glock's (1972) Five-Dimensional Model and Pargament's (1997) theory of religious coping, have been proposed to explain the components of religiosity and how they function to help individuals cope with life challenges.

To better understand religiosity, the Fetzer Institute (1999), in collaboration with the National Institute on Aging, established a working group that examined aspects of religiosity and developed a comprehensive model to explain this construct. The working group stated that religiosity cannot be studied as a one-dimensional variable; instead, it posited 12 components of religiosity that must be examined individually. These components are daily spiritual experiences, meaning, values, beliefs, private religious practices, organizational religiousness, religious support, religious coping, forgiveness, religious history, commitment, and religious preferences. The working group also posited five dimensions of forgiveness that are important for religious individuals: feeling forgiven by God, feeling forgiven by others, forgiving others, forgiving oneself, and confession. Additional components of religiosity included spiritual maturity and religious commitment (referring to the importance individuals place on their religious beliefs, including contributions of time and money) and religious preference (i.e., the tradition or denomination espoused by the individual). The working group defined each component in detail and operationalized the components through an assessment measure, which has been used extensively in research on religiosity and well-being.

\section{Wellness}

Dunn (1961), one of the original scholars in the field of wellness, defined wellness as "an integrated method of functioning which is oriented toward maximizing the potential of which the individual is capable" (p. 4). Myers et al. (2000) defined it as "a way of life oriented toward optimal health and well-being, in which body, mind, and spirit are integrated by the individual to live life more fully within the human and natural community" (p. 252). A variety of models and theories relating to wellness have been proposed (e.g., Dunn, 1961; Hettler, 1984). On the basis of previous research from a variety of disciplines (e.g., psychology, medicine, health promotion, anthropology) and the writings of Adler (Ansbacher \& Ansbacher, 1956), Myers et al. presented a holistic model of wellness and prevention over the life span consisting of six life tasks: spirituality, selfdirection, work, leisure, friendship, and love. This theoretical model was subsequently revised on the basis of empirical data, resulting in a new model: the Indivisible Self Model of Wellness (IS-Wel; Myers \& Sweeney, 2005a).

The IS-Wel (Myers \& Sweeney, 2005a) was defined through structural equation modeling and includes a single higher order wellness factor (Total Wellness), five second-order factors of the self (Creative Self, Coping Self, Social Self, Essential Self, and Physical Self), and 17 third-order factors grouped within the second-order factors. Unlike other wellness models, both the Wheel of Wellness (Witmer, Sweeney, \& Myers, 1998) and the IS-Wel are grounded in counseling theory as opposed to physical health sciences and include a broad range of psychological and physiological factors that contribute to holistic wellness (Hermon \& Hazler, 1999). In both models, one's wellness in any area (e.g., friendship) has an impact on all other aspects of holistic wellness, and vice versa.

Dew and Newton (2005) reviewed studies on gender and wellness and underscored the need for research in this area. In particular, they noted that most of the existing research has used convenience samples of predominantly middle- to upper-class European American individuals, excluding lower socioeconomic and racial/ethnic minority persons. These authors also cited several studies in which the wellness of women was statistically significantly lower than that of men, again emphasizing the need both to study women's wellness and to develop strategies for enhancing wellness in this population at risk for specific challenges to mental health and holistic wellness (Myers \& Gill, 2004).

\section{Method}

Following receipt of approval from the institutional review board, a diverse group of adult female participants residing in nonmetropolitan areas, whose income level fell into the federal criteria for poor or near poverty, were recruited. All participants were volunteers living in a rural area of one state in the Southeast who were receiving social services from agencies such as the Salvation Army, nutrition centers, and a local community college. Because of the nature of the sampling procedure, which was a modified snowball procedure that included participants recruited by staff at social service agencies, an accurate response rate cannot be determined.

\section{Participants}

A total of 167 women volunteered to participate in the study. More than half $(58.1 \%$ ) were European American, $17.4 \%$ were African American, $6.0 \%$ were Native American, $3.0 \%$ were Latino American, $2.4 \%$ were Asian/Pacific Islander, and $6.0 \%$ endorsed "other." Twelve participants (7.2\%) did not indicate their race/ethnicity. (Percentages in this section may not equal $100 \%$ because of rounding.) Nearly two thirds $(64.1 \%)$ were between the ages of 18 and 35 years, $18.6 \%$ were between the 
ages of 35 and 55 years, and $12.0 \%$ were 55 years or older. Nine participants (5.4\%) did not indicate their age. A minority of participants $(8.4 \%)$ reported not completing high school, more than half $(55.7 \%)$ reported having a high school degree, $15.0 \%$ had a trade or technical school degree, $9.6 \%$ had an associate's degree, and $6.6 \%$ had a bachelor's degree or higher. Eight participants $(4.8 \%)$ did not indicate their educational level. Less than half of the participants $(46.7 \%)$ had an income of less than $\$ 9,500 ; 25.1 \%$ reported an income level between $\$ 9,500$ and $\$ 15,750 ; 6.0 \%$ had incomes between $\$ 15,750$ and $\$ 18,500 ; 11.4 \%$ had incomes between $\$ 18,500$ and $\$ 27,000$; and $10.8 \%$ indicated "other" for their level of income.

\section{Instruments}

Participants completed four paper-and-pencil assessment instruments: the Spirituality Assessment Scale (SAS; Howden, 1993), the Fetzer Brief Multidimensional Measure of Religiousness/Spirituality Scale (BMMRS; Fetzer Institute, 1999), the Five Factor Wellness Inventory (5F-Wel; Myers \& Sweeney, 2005b), and a brief demographics questionnaire.

SAS. Howden (1993) developed the SAS to assess levels of spirituality in a model, which is similar to Westgate's (1996) Spiritual Wellness model, is well conceptualized, and offers universal language (Harper \& Gill, 2005). The SAS consists of 28 questions and four subscales, including Purpose and Meaning in Life, Transcendence, Unifying Interconnectedness, and Inner Resources. The items are rated on a 6-point Likert-type scale ranging from 1 (strongly disagree) to 6 (strongly agree); possible scores can range from 28 to 168 (Howden, 1993). Scores in the 140-160 range represent evidence of strong, positive spirituality, and scores in the 84-112 range represent fair or mixed spirituality. Spiritual distress is associated with scores ranging from 28 to 56 . Item-to-total correlations varied from .30 to .70 (Howden, 1993). Internal consistency reliability alpha for the current study was .93 for the total scale; subscales yielded coefficient alpha reliabilities of .82 (Purpose and Meaning in Life), . 72 (Transcendence), .82 (Unifying Interconnectedness), and .88 (Inner Resources).

Initial evidence for construct validity of the SAS was established using a principal-component factor analysis (Howden, 1993). Further evidence of validity was established through Pearson product-moment correlations, which resulted in no statistically significant relationship between the factors of spirituality and reports of religiousness and attendance at religious events. As a result, this instrument was shown to distinguish between religiousness and spirituality as discrete constructs.

BMMRS. The 40-item BMMRS was developed to measure the 12 dimensions of religiosity proposed by the Fetzer Institute working group; only six of the subscales were used in this study. Questions are answered using a Likert-type scale with differing numeric responses available for each subscale. A total scale score or individual subscale scores can be obtained. Together, the six BMMRS subscales of interest in this study yielded an internal consistency reliability of .93 .
Internal consistency coefficient alphas for the six individual subscales used in the current study were as follows: Daily Spiritual Experiences (five items) $=.91$, Forgiveness (three items $)=.53$, Private Religious Practices (five items) $=.80$, Religious and Spiritual Coping (seven items) $=.69$, Religious Support (two items) $=.55$, and Organizational Religiousness (two items) $=.78$. The Meaning subscale was not included in this study because the working group did not make a final decision on the domain and because meaning in life is part of Howden's (1993) SAS. The Values and Beliefs subscale was not included because the subscale was unreliable as evidenced by a low alpha (.12), and the Overall Self-Ranking subscale was not included because the two-item subscale did not add unique data for analysis. Subscales for religious/spiritual history, commitment, and religious preference were not included because they all require qualitative responses.

$5 \mathrm{~F}$-Wel. The $5 \mathrm{~F}-\mathrm{Wel}$ is a 73 -item instrument developed through structural equation modeling (Hattie, Myers, \& Sweeney, 2004) designed to assess each of the factors in the IS-Wel (Myers \& Sweeney, 2005a). Each item is a statement (e.g., "I am an active person") that requires a response on a 4-point Likert-type scale ranging from 4 (strongly agree) to 1 (strongly disagree). A subscale score is the sum of the responses to each item in the subscale. A linear transformation is used to place all subscales on a common metric ranging from 25 to 100 ; higher scores indicate higher levels of wellness. The instrument provides scores for Total Wellness, a factor composed of the sum of all 73 items; five secondorder factors; and 17 third-order factors that group within the second-order factors. In this study, only the higher order Total Wellness factor and the five second-order factors were examined. The 17 third-order factors were excluded to reduce the number of analyses and the potential for spurious results. In the current study, the $5 \mathrm{~F}$-Wel yielded an internal consistency reliability of .94; Cronbach's alpha coefficients for the five second-order factors were as follows: Essential Self $=.83$, Creative Self $=.85$, Physical Self $=.86$, Coping Self $=.78$, and Social Self $=.83$.

Demographics questionnaire. In addition to the three instruments described in this section, we used a demographics form to capture the following data: age, income level, number of individuals residing in the home, and eligibility for government subsidies. The purpose of this form was to ensure that the participants met the income and age requirements necessary for their responses to be analyzed. Of the 194 packets that were collected, only 167 participants qualified as low-income women on the basis of the demographics questionnaire.

\section{Data Analyses}

With the exception of the all-possible-subsets regression and commonality analysis, all data were analyzed using SPSS (Version 14.0). Descriptive statistics and Cronbach's alpha coefficients were computed for all instruments and all subscales. A series of Pearson product-moment correlations 
were conducted to test the first research question. The second research question was evaluated using analyses of variance (ANOVAs) to identify mean differences in spirituality, religiosity, and wellness on the basis of race/ethnicity. Simultaneous multiple regression analyses revealed the percentage of variance in wellness accounted for by spirituality and religiosity, addressing the final research question; all-possible-subsets regression and commonality analysis were used to investigate the particular aspects of spirituality and religiosity that contributed to wellness. An alpha level of .05 was established to determine statistical significance; alpha levels of $<.01$ are also reported.

\section{Results}

\section{Research Question 1}

The first research question examined the relationships among spirituality, religiosity, and wellness for low-income, rural women. The results of Pearson product-moment correlations computed between subscales of all instruments (the SAS, the BMMRS, and the 5F-Wel) are shown in Tables 1 and 2. As shown in Table 1, correlations among all the SAS subscales were statistically significant, correlations among all the BMMRS subscales were statistically significant, and 23 of 24 correlations among the SAS and BMMRS subscales were statistically significant, all at the .01 level. Only the correlation between the SAS Transcendence subscale and the BMMRS Religious Support subscale was not statistically significant.

Patterns of higher correlations were found between the BMMRS Daily Spiritual Experiences subscale and SAS subscales such as Purpose and Meaning in Life $(r=.51)$ and Inner Resources $(r=.60)$. Similarly, the BMMRS Daily Spiritual Experiences subscale was strongly correlated with the BMMRS subscales of Forgiveness $(r=.61)$, Private Religious Practices $(r=.76)$, Religious and Spiritual Coping $(r=$
.72), and Organizational Religiousness $(r=.61)$. Patterns of lower correlations were found between most SAS subscales and BMMRS subscales. For example, small correlations were found between the SAS Unifying Interconnectedness subscale and the BMMRS subscales of Religious Support $(r$ $=.22)$ and Organizational Religiousness $(r=.24)$. Similarly, a small correlation was found between the SAS Transcendence subscale and the BMMRS Organizational Religiousness subscale $(r=.25)$.

As can be seen in Table 2, all correlations between the 5F-Wel Total Wellness score and the SAS and BMMRS subscales were statistically significant. Correlations were highest between the $5 \mathrm{~F}-$ Wel Total Wellness score and scores on the four SAS subscales and ranged from $r=.50$ for Purpose and Meaning in Life to $r=.58$ for Unifying Interconnectedness. A similar pattern of higher correlations between the SAS subscales and the $5 \mathrm{~F}-$ Wel subscales was observed. Correlations between the $5 \mathrm{~F}-$ Wel Total Wellness score and the six BMMRS subscales ranged from $r=.30$ for Organizational Religiousness to $r=.46$ for Religious and Spiritual Coping.

Similarly, correlations between the $5 \mathrm{~F}-$ Wel Essential Self subscale and all the SAS and BMMRS subscales were statistically significant at the $p<.01$ level; correlations ranged from $r=.32$ for the BMMRS Religious Support subscale to $r=.59$ for the BMMRS subscales of Daily Spiritual Experiences and Private Religious Practices. Correlations between the 5F-Wel Physical Self subscale and the SAS subscales ranged from $r=.21(p<.01)$ for Purpose and Meaning in Life to $r=.32(p<.01)$ for Transcendence; these correlations were low compared with other findings. Similarly, correlations between the 5F-Wel Physical Self subscale and the BMMRS subscales were small and ranged from $r=$ $.16(p<.05)$ for Daily Spiritual Experiences and Religious Support to $r=.30(p<.01)$ for Private Religious Practices. The 5F-Wel Coping Self subscale was not correlated with the BMMRS Religious Support subscale. The 5F-Wel Social Self subscale correlated with the BMMRS subscales of Daily

\section{TABLE 1}

\section{Pearson Product-Moment Correlations and Cronbach's Alpha Coefficients for the SAS and BMMRS-} Subscales $(N=167)$

\begin{tabular}{|c|c|c|c|c|c|c|c|c|c|c|}
\hline Scale and Subscale & 1 & 2 & 3 & 4 & 5 & 6 & 7 & 8 & 9 & 10 \\
\hline \multicolumn{11}{|l|}{ SAS } \\
\hline 1. Purpose and Meaning in Life & .82 & - & & & & & & & & \\
\hline 2. Inner Resources & .77 & .88 & - & & & & & & & \\
\hline 3. Unifying Interconnectedness & .57 & .76 & .82 & - & & & & & & \\
\hline 4. Transcendence & .53 & .72 & .67 & .72 & - & & & & & \\
\hline \multicolumn{11}{|l|}{ BMMRS } \\
\hline 5. Daily Spiritual Experiences & .51 & .60 & .46 & .40 & .91 & - & & & & \\
\hline 6. Forgiveness & .44 & .52 & .49 & .38 & .61 & .53 & - & & & \\
\hline 7. Private Religious Practices & .35 & .48 & .37 & .41 & .76 & .51 & .80 & - & & \\
\hline 8. Religious and Spiritual Coping & .35 & .49 & .40 & .33 & .72 & .51 & .65 & 69 & - & \\
\hline 9. Religious Support & .30 & .32 & .22 & $.07^{a}$ & .45 & .42 & .44 & .41 & .55 & - \\
\hline 10. Organizational Religiousness & .30 & .33 & .24 & .25 & .61 & .45 & .71 & .44 & .55 & .78 \\
\hline
\end{tabular}

Note. Cronbach's alpha coefficients are on the diagonal and in boldface. All correlations were significant at $p<.01$. SAS $=$ Spirituality Assessment Scale; BMMRS = Fetzer Brief Multidimensional Measure of Religiousness/Spirituality Scale.

a The correlation between the SAS Transcendence subscale and the BMMRS Religious Support subscale was not statistically significant. 
TABLE 2 Pearson Product-Moment Correlations for the 5F-Wel Total Wellness Score and Subscales,
SAS Subscales, and BMMRS Subscales $(N=167)$

\begin{tabular}{|c|c|c|c|c|c|c|}
\hline \multirow[b]{2}{*}{ Scale and Subscale } & \multicolumn{6}{|c|}{ 5F-Wel } \\
\hline & Total Wellness & Essential Self & Creative Self & Physical Self & Coping Self & Social Self \\
\hline \multicolumn{7}{|l|}{ SAS } \\
\hline 1. Purpose and Meaning & & & & & & \\
\hline in Life & $.50^{* *}$ & $.47^{*}$ & $.43^{* *}$ & $.21^{* *}$ & $.45^{* *}$ & $.45^{* *}$ \\
\hline \multirow{2}{*}{\multicolumn{7}{|c|}{ 3. Unifying }} \\
\hline & & & & & & \\
\hline $\begin{array}{l}\text { Interconnectedness } \\
\text { 4. Transcendence }\end{array}$ & $.58^{* *}$ & $.58^{* *}$ & $.54^{* *}$ & $.28^{* *}$ & $.50^{* *}$ & $.35^{* *}$ \\
\hline \multirow{3}{*}{\multicolumn{7}{|c|}{$\begin{array}{l}\text { BMMRS } \\
\text { 5. Daily Spiritual }\end{array}$}} \\
\hline & & & & & & \\
\hline & & & & & & \\
\hline Experiences & $37^{* *}$ & $.59^{* *}$ & $.23^{* *}$ & $.16^{*}$ & $.26^{* *}$ & $.15^{*}$ \\
\hline $\begin{array}{l}\text { 6. Forgiveness } \\
\text { 7. Private Religious }\end{array}$ & $.38^{* *}$ & $.46^{* *}$ & $.26^{* *}$ & $.19^{*}$ & $.34^{* *}$ & $.22 * *$ \\
\hline $\begin{array}{l}\text { Practices } \\
8 \text { Religious and Sniritual }\end{array}$ & $.43^{* *}$ & $.59^{* *}$ & $.30^{* *}$ & $.30 * *$ & $.30^{* *}$ & 12 \\
\hline $\begin{array}{l}\text { 8. Religious and Spiritual } \\
\text { Coping }\end{array}$ & $.46^{* *}$ & $.51^{*}$ & $.21^{*}$ & .10 & $.16^{*}$ & .03 \\
\hline 9. Religious Support & $.32 *$ & $.32 *$ & .09 & $.16^{*}$ & .11 & 10 \\
\hline $\begin{array}{l}\text { 10. Organizational } \\
\text { Religiousness }\end{array}$ & $.30^{*}$ & $48^{*}$ & $.18^{*}$ & $.22 * *$ & $.18^{*}$ & .07 \\
\hline
\end{tabular}

Note. $5 \mathrm{~F}-\mathrm{Wel}=$ Five Factor Wellness Inventory; SAS = Spirituality Assessment Scale; BMMRS = Fetzer Brief Multidimensional Measure of Religiousness/Spirituality Scale.

${ }^{*} p<.05 . " * p<.01$.

Spiritual Experiences $(r=.15, p<.05)$ and Forgiveness $(r$ $=.22, p<.01$ ).

\section{Research Question 2}

A series of one-way ANOVAs was used to test for mean differences in spirituality, religiosity, and wellness on the basis of participants' race/ethnicity. On the basis of race/ethnicity, there were no statistically or practically significant differences in spirituality, $F(5,149)=2.21, p=.06, \eta^{2}=.03$; religiosity, $F(5,149)=2.03, p=.08, \eta^{2}=.06$; or wellness, $F(5,149)=$ $1.27, p=.28, \eta^{2}=.04$.

\section{Research Question 3}

Simultaneous multiple regression using the forced-entry method was used to determine the extent to which the total scores for spirituality and religiosity predicted total wellness. An initial regression analysis indicated that spirituality and religiosity were statistically, $F(2,164)=52.84, p<.001$, and practically $\left(R^{2}=.39\right.$, adjusted $\left.R^{2}=.38\right)$ significant predictors of total wellness. Because the predictor variables were correlated and likely to explain some of the same variance in total wellness, an analysis of beta weights and structure coefficients was used to determine the degree to which spirituality and religiosity were related to total wellness (Courville \& Thompson, 2001; Henson, 2002). Examination of structure coefficients indicated that spirituality $(\beta=$ $\left..52, p<.01, r_{s}=.98, r_{s}^{2}=.96\right)$ accounted for nearly all the predicted variance in wellness, and religiosity $(\beta=.16, p=$ $\left..04, r_{s}=.75, r_{s}^{2}=.56\right)$ accounted for more than half of the predicted variance in wellness.

Because spirituality and religiosity emerged as strong, statistically significant predictors of wellness when using the total scores, we used all-possible-subsets regression to identify the most parsimonious, theoretically consistent model of spirituality and religiosity that led to the greatest prediction of total wellness. This procedure was carried out using Nimon, Lewis, Kane, and Haynes's (2008) An R Package to Compute Commonality Coefficients in the Multiple Regression Case. We included in the model all four SAS subscales and all six BMMRS subscales; thus, this analysis included examination of 1,023 unique combinations of explanatory variables. In this case, all 10 subscale variables predicted $45.16 \%$ of the variance in total wellness; however, examination of alternative subsets led us to select just three variables that explained $42.11 \%$ of the variance in total wellness. The SAS Purpose and Meaning in Life subscale, the SAS Unifying Interconnectedness subscale, and the BMMRS Private Religious Practices subscale were statistically, $F(3,163)$ $=39.54, p<.001$, and practically $\left(R^{2}=.42\right.$, adjusted $\left.R^{2}=.41\right)$ significant predictors of total wellness; beta weights, $p$ values, and structure coefficients are displayed in Table 3.

Zientek and Thompson (2006) recommended use of commonality analysis to aid in interpretation of regressions involving correlated predictors; therefore, we used a followup commonality analysis to better understand the degree to which the SAS Purpose and Meaning in Life subscale, the SAS Unifying Interconnectedness subscale, and the BMMRS 
TABLE 3

All-Possible-Subsets Regression Results for Predicting Variance in Total Wellness Explained by SAS and BMMRS Subscales

\begin{tabular}{|c|c|c|c|c|c|c|}
\hline Predictor & $\beta$ & Significant $\beta$ & Unique & Common & Total & $r_{s}^{2}$ \\
\hline SAS Purpose and Meaning in Life & .21 & .005 & .03 & .23 & .26 & 61.90 \\
\hline SAS Unifying Interconnectedness & .38 & $<.001$ & .10 & .25 & .35 & 83.33 \\
\hline BMMRS Private Religious Practices & .22 & .001 & .04 & .15 & .19 & 45.24 \\
\hline
\end{tabular}

Note. For the all-possible-subsets regression model, $F(3,163)=39.54, p<.001\left(R^{2}=.42\right.$, adjusted $\left.R^{2}=.41\right)$. SAS $=$ Spirituality Assessment Scale; BMMRS = Fetzer Brief Multidimensional Measure of Religiousness/Spirituality Scale; Unique = predictor's unique effect; Common = sum of predictor's common effects; Total $=$ sum of predictor's unique and common effects; $r_{s}^{2}=$ Total divided by $R^{2}$ (represented as a percentage).

Private Religious Practices subscale contributed, individually and collectively, to the explained variance in wellness. Results of the commonality analysis are depicted in Table 3, and relationships among these unique and common predictors are depicted in Figure 2.

\section{Discussion}

The purpose of this study was to examine the relationships among spirituality, religiosity, and wellness for low-income, rural women. Statistically significant, positive correlations were found between all but one of the SAS and BMMRS subscales and between all SAS and 5F-Wel subscales. Statistically significant, positive correlations were found between the $5 \mathrm{~F}$-Wel Total Wellness score and the 5F-Wel Essential Self

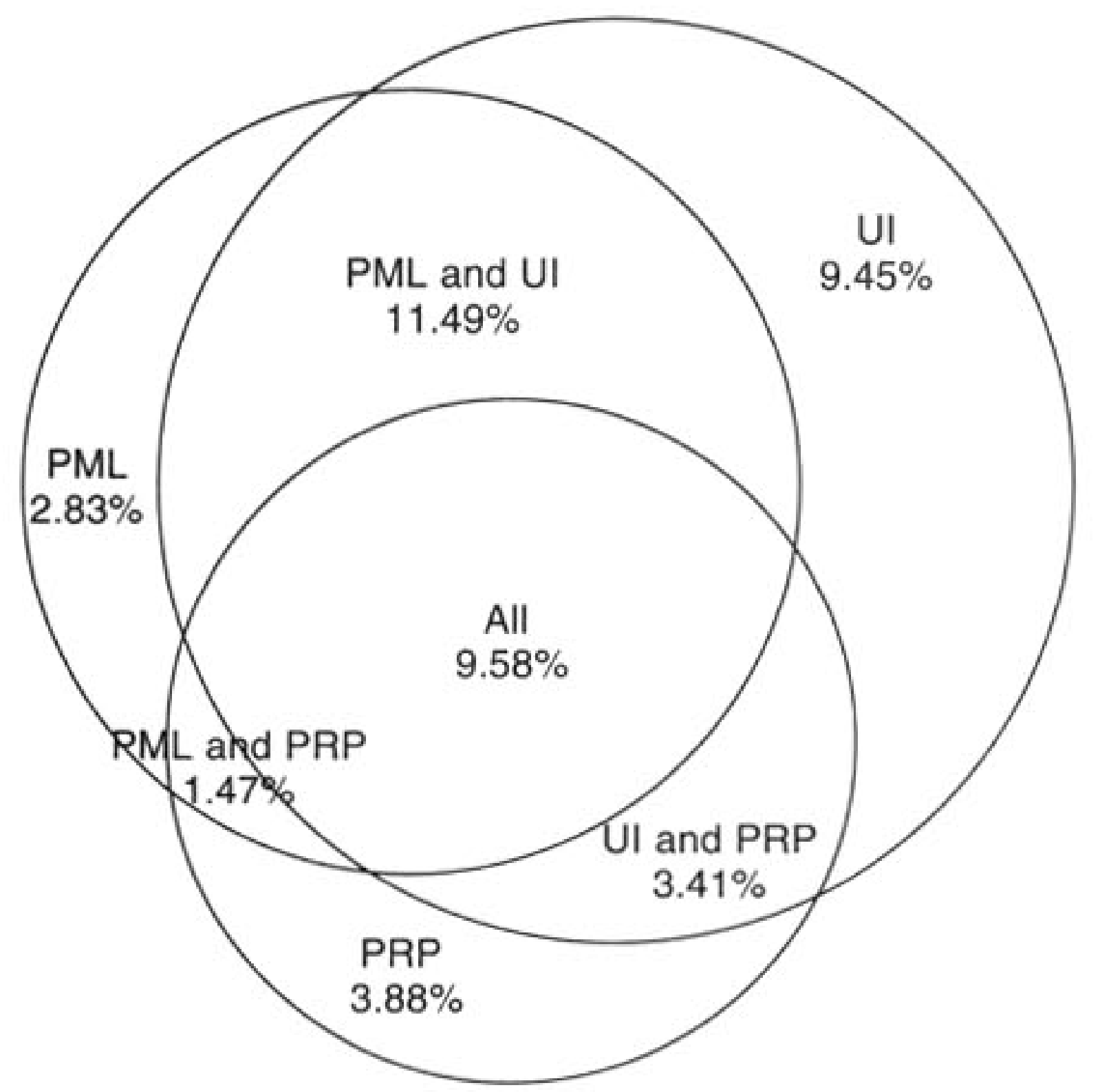

FIGURE 2

\section{Commonality Partitions of Explained Variance in Wellness}

Note. UI = Unifying Interconnectedness subscale of the Spirituality Assessment Scale (SAS); PML = Purpose and Meaning in Life subscale of the SAS; All = all three subscales; PRP = Private Religious Practices subscale of the Fetzer Brief Multidimensional Measure of Religious/Spirituality Scale. subscale and all BMMRS subscales. Seventeen of 24 correlations between the BMMRS subscales and the remaining four 5F-Wel subscales (Creative Self, Physical Self, Coping Self, and Social Self) were positive and statistically significant, with the BMMRS subscales of Religious and Spiritual Coping and Religious Support having the lowest intercorrelations with these $5 \mathrm{~F}-$ Wel subscales. Together, total scores for religiosity and spirituality accounted for $39 \%$ of the variance in total wellness for the low-income, rural women in the sample.

The nearly universal high correlations among the SAS subscales and the BMMRS subscales were not unexpected, given the extensive literature relating the variables of spirituality and religiosity. Nevertheless, an examination of the subscales with patterns of high and low intercorrelations raises the possibility that for poor, rural women, spirituality and religiosity may represent two different concepts. On the other hand, the high correlations found between the BMMRS Daily Spiritual Experiences subscale and all other BMMRS subscales, as well as all the subscales of the SAS, demonstrates a strong relationship between daily spiritual experiences and both religiosity and spirituality. The items in this subscale (e.g., "I feel a deep inner peace or harmony" and "I feel God's love for me, directly") measure experiences that may be defined as either religious or spiritual, depending on the particular definition used. Hence, being spiritual for these women may be defined in terms of engaging in regular (daily) religious or spiritual practice. Although such a conclusion is impossible to make on the basis of the current findings, it does raise the question of the relationship of regular religious or spiritual practice as central to wellness for these women.

The BMMRS Daily Spiritual Experiences subscale was also highly related to all the $5 \mathrm{~F}$-Wel subscales, but patterns of higher correlations were found between the $5 \mathrm{~F}$-Wel subscales and all of the SAS subscales, indicating that for poor, rural women, spirituality and wellness may be more highly related than religiosity and wellness. Noteworthy are the specific $5 \mathrm{~F}-$ Wel subscales that did not correlate with BMMRS subscales; for instance, the $5 \mathrm{~F}-$ Wel Social Self subscale did not have a statistically significant correlation with four of the BMMRS subscales, including Religious Support and Organizational Religiousness, perhaps indicating that for the participants in our sample, social interaction is not a portion of religiosity or 
religiosity is not a part of their friendship and love patterns. This finding is contrary to the findings of prior studies in which social support has been found to be a major component of religious practice when measured by church attendance (e.g., Koenig, 1991). Further study is needed to determine whether the current results are due to anomalies in the sample, factors specific to the measures used, or possible within-group variability that was impossible to assess given the cell sizes in the current design.

It was interesting that differences in spirituality, religiosity, and wellness were not found on the basis of race/ethnicity. A number of studies cited in Myers and Sweeney (2005a) revealed differences in wellness and spiritual wellness on the basis of race/ethnicity. For example, several studies cited in their literature review revealed higher levels of spiritual wellness among African Americans than among European Americans. The lack of such relationships in the current study suggests that differences found in this sample were due to specific characteristics of the population, notably rural and poverty status.

This was the first study to examine wellness in a population of poor, rural women. If our findings can be replicated with additional, similar populations, including with poor, rural men, understanding of these populations would be greatly enhanced. In addition, qualitative studies would also contribute to a better understanding of these seemingly contradictory results. Clarification of these results could aid in the process of making evidence-based helping interventions available to counselors, perhaps producing a noteworthy, positive impact on these underserved populations.

The results of the all-possible-subsets regression revealed the specific components of spirituality and religiosity that help explain wellness in this sample of poor, rural women. These variables - purpose and meaning in life, unifying interconnectedness, and private religious practices - provide a starting place for developing helping interventions to increase wellness among low-income women living in rural areas. It is interesting that unifying interconnectedness was the strongest single predictor of the explained variance in wellness, but when combined with purpose and meaning in life, these variables accounted for a larger percentage of the variance than any other single predictor or combination of predictors. This interplay is not unexpected, given that purpose and meaning in life has been identified throughout the counseling literature and by multiple theorists as central to positive mental health and well-being (Moberg \& Brusek, 1978; Myers \& Sweeney, 2005a). In addition, although establishing purpose and meaning in life is unique to the individual, unifying interconnectedness (e.g., connections with the universe and with others) may in fact represent a method for poor, rural women to establish purpose and meaning in life. Furthermore, private religious practices, which also predicted a portion of the common variance in explained wellness, may provide these women a structure for connecting with the universe and the Divine, thereby enhancing purpose and meaning in life. Counselors may find that helping women explore and clarify these aspects of their connections, purpose, and practices could enhance their holistic wellness.

It would be noteworthy to replicate this study with women in other geographic areas and with sufficient numbers of women representing diverse racial/ethnic backgrounds to determine whether the same relationships found here exist across populations. A factor to consider in such studies would be the reading level of the instruments, because some of the participants in our study had difficulty responding to certain questions, skipped questions, or chose to write qualitative responses rather than selecting one response for multiple-choice questions. These reactions were most pronounced at settings other than the community college and may have affected the results in unknown ways.

\section{Implications for Counseling}

Counselors working with poor, rural women can develop and implement strength-based interventions with confidence using the findings from this study. Strong correlations among the SAS subscales, the BMMRS subscales (e.g., the Daily Spiritual Experience subscale), and the $5 \mathrm{~F}$-Wel subscales suggest that modifications in spirituality may result in changes in wellness for poor, rural women. Furthermore, because of the factor structure of wellness, positive alterations in one wellness area will improve overall wellness for these women.

Because specific components of spirituality and religiosity accounted for a large portion of the variance in wellness in this study, counselors can assist clients in custom designing interventions that are evidence-based tools for improving holistic wellness. For instance, specific interventions based on unifying interconnectedness, purpose and meaning in life, and private religious practices may be particularly effective for low-income, rural women because of the contributions these areas make to wellness. To help increase overall wellness for these women, counselors can use interventions aimed at unifying interconnectedness, such as assisting clients with identifying events that produce positive feelings of kinship with other people, connections with all of life, and the feeling of being part of a community and then increasing the occurrence. Encouraging the interested client in involvement in personal activities such as prayer, meditation, and the reading of sacred materials in an informal manner and outside of the public domain can also be a strength-based method for improving wellness. Furthermore, ideas for identifying and encouraging purpose and meaning in life are prevalent throughout the literature (Myers et al., 2000).

Interventions involving purpose and meaning in life and unifying interconnectedness may be particularly salient, given that these combined variables accounted for a sizable portion of the variance in wellness for these women. Evidence-based interventions aimed at increasing a sense of purpose and meaning in life may include assisting clients in finding a general 
sense of belonging, identifying goals and direction for their lives, and finding relationships and activities that provide fulfillment. Encouragement to explore what gives purpose and meaning to her life could be especially useful for improving wellness for poor, rural women.

\section{Conclusion}

This study provided a preliminary examination of the relationships among spirituality, religiosity, and wellness for poor, rural women. Spirituality and religiosity did account for a statistically significant proportion of the variance in their wellness, and differences in spirituality, religiosity, and wellness by race/ethnicity were not found. Further studies conducted with larger, more racially/ethnically diverse samples should be considered so that these results, which in some ways seem contrary to those of previous studies, can be clarified. Qualitative studies may also help counselors more fully understand both the meaning of spiritual and religious factors and the contributions of these variables to wellness among poor, rural women. In the meantime, the results of this study may be used as a foundation for helping low-income, rural women experience greater wellness through strength-based interventions focused on their spiritual and religious beliefs and behaviors.

\section{References}

Amato, P. R., \& Zuo, J. (1992). Rural poverty, urban poverty, and psychological well-being. Sociological Quarterly, 33, 229-241.

Ansbacher, H. L., \& Ansbacher, R. R. (Eds.). (1956). The individual psychology of Alfred Adler. New York, NY: Basic Books.

Ashing, K. T., Padilla, G., Tejero, J., \& Kagawa-Singer, M. (2003). Understanding the breast cancer experience of Asian American women. Psycho-Oncology, 12, 38-58.

Barusch, A. S. (1999). Religion, adversity, and age: Religious experiences of low-income elderly women. Journal of Sociology and Social Welfare, 26, 125-142.

Brome, D. R., Owens, M. D., Allen, K., \& Vevaina, T. (2000). An examination of spirituality among African American women in recovery from substance abuse. Journal of Black Psychology, $26,470-486$.

Brotherson, S. E., \& Soderquist, J. (2002). Coping with a child's death: Spiritual issues and therapeutic implications. Journal of Family Psychotherapy, 13, 53-86.

Cashwell, C. S., \& Young, J. S. (Eds.). (2005). Integrating spirituality and religion into counseling. Alexandria, VA: American Counseling Association.

Chandler, C. K., Holden, J. M., \& Kolander, C. A. (1992). Counseling for spiritual wellness: Theory and practice. Journal of Counseling \& Development, 71, 168-175.

Courville, T., \& Thompson, B. (2001). Use of structure coefficients in published multiple regression articles: $\beta$ is not enough. $E d u$ cational and Psychological Measurement, 61, 229-248.
Dabney, D. C. (2000). Resilient women: Childhood sexual abuse of African-American women and their coping and healing. Dissertation Abstracts International: Section A. Humanities and Social Sciences, 61(04), 1629.

Dew, B. J., \& Newton, K. S. (2005). Gender, sexual orientation, and wellness: Research implications. In J. E. Myers \& T. J. Sweeney (Eds.), Counseling for wellness: Theory, research, and practice (pp. 127-138). Alexandria, VA: American Counseling Association.

Dunbar, D., \& Jeannechild, N. (1996). The stories and strength of women who leave battering relationships. In B. J. Brothers (Ed.), Couples and change (pp. 149-171). New York, NY: Haworth Press.

Dunn, H. L. (1961). High-level wellness. Arlington, VA: Beatty.

Elkins, D. N., Hedstrom, L. J., Hughes, L. L., Leaf, J. A., \& Saunders, C. (1988). Toward a humanistic phenomenological spirituality: Definition, description, and measurement. Journal of Humanistic Psychology, 28, 5-18.

England, H., \& Finch, J. (1991). Rural women: A thematic perspective on midlife. Canadian Journal of Counselling, 25, 594-602.

Fetzer Institute. (1999). Multidimensional measurement of religiousness/spirituality for use in health research. Kalamazoo, MI: Author.

Glock, C. Y. (1972). On the study of religious commitment. In J. E. Faulkner (Ed.), Religion's influence in contemporary society: Readings in the sociology of religion (pp. 38-56). Columbus, $\mathrm{OH}$ : Charles E. Merrill.

Hackney, C. H., \& Sanders, G. S. (2003). Religiosity and mental health: A meta-analysis of recent studies. Journal for the Scientific Study of Religion, 42, 43-55.

Harper, M. C., \& Gill, C. S. (2005). Assessing the client's spiritual domain. In C. S. Cashwell \& J. S. Young (Eds.), Integrating spirituality and religion into counseling (pp. 31-62). Alexandria, VA: American Counseling Association.

Hattie, J. A., Myers, J. E., \& Sweeney, T. J. (2004). A factor structure of wellness: Theory, assessment, analysis, and practice. Journal of Counseling \& Development, 82, 354-364.

Haynie, D. L., \& Gorman, B. K. (1999). A gendered context of opportunity: Determinants of poverty across urban and rural labor markets. The Sociological Quarterly, 40, 177-200.

Henson, R. K. (2002). The logic and interpretation of structure coefficients in multivariate general linear model analyses. Retrieved from ERIC database. (ED467381)

Hermon, D. A., \& Hazler, R. J. (1999). Adherence to a wellness model and perceptions of psychological well-being. Journal of Counseling \& Development, 77, 339-343.

Hettler, B. (1984). Wellness: Encouraging a lifetime pursuit of excellence. Health Values, 8, 13-17.

Hill, P. C., \& Pargament, K. I. (2003). Advances in the conceptualization and measurement of religion and spirituality: Implications for physical and mental health research. American Psychologist, $58,64-74$.

Holt, C. L., Clark, E. M., Kreuter, M. W., \& Rubio, D. M. (2003). Spiritual health locus of control and breast cancer beliefs among urban African American women. Health Psychology, 22, 294-299. 
Howden, J. W. (1993). Development and psychometric characteristics of the Spirituality Assessment Scale. Dissertation Abstracts International: Section B. Sciences and Engineering, 54(01), 166.

Koenig, H. G. (1991). Religion and prevention of illness in later life. Prevention in Human Services, 10, 69-89.

Koenig, H. G., \& Larson, D. B. (2001). Religion and mental health: Evidence for an association. International Review of Psychiatry, 13, 67-78.

Lindgren, K. N., \& Coursey, R. D. (1995). Spirituality and serious mental illness: A two-part study. Psychological Rehabilitation Journal, 18, 93-111.

Mendelson, C. (2002). Health perceptions of Mexican American women. Journal of Transcultural Nursing, 13, 210-217.

Miller, G. (1999). The development of the spiritual focus in counseling and counselor education. Journal of Counseling \& Development, 77, 498-501.

Moberg, D. O., \& Brusek, P. M. (1978). Spiritual well-being: A neglected area in quality of life research. Social Indicators Research, 5, 303-323.

Myers, J. E. (1990, May). Wellness throughout the life span. Guidepost, p. 11.

Myers, J. E., \& Gill, C. S. (2004). Poor, rural and female: Understudied, under-counseled, more at-risk. Journal of Mental Health Counseling, 26, 225-242.

Myers, J. E., \& Sweeney, T. J. (Eds.). (2005a). Counseling for wellness: Theory, research, and practice. Alexandria, VA: American Counseling Association.

Myers, J. E., \& Sweeney, T. J. (2005b). The Five Factor Wellness Inventory. Palo Alto, CA: Mind Garden.

Myers, J. E., Sweeney, T. J., \& Witmer, J. M. (2000). Counseling for wellness: A holistic model for treatment planning. Journal for Counseling \& Development, 78, 251-266.
Nimon, K., Lewis, M., Kane, R., \& Haynes, R. M. (2008). An R package to compute commonality coefficients in the multiple regression case: An introduction to the package and a practical example. Behavior Research Methods, 40, 457-466.

Pargament, K. I. (1997). The psychology of religion and coping: Theory, research, practice. New York, NY: Guilford Press.

Reutter, L., Neufield, A., \& Harrison, M. (2001). Nursing research on the health of low-income women. Public Health Nursing, $15,109-122$.

Seaward, B. L. (1995). Reflections on human spirituality for the worksite. American Journal of Health Promotion, 9, 165-168.

United Nations. (1995). The United Nations Fourth World Conference on Women. Retrieved from http://www.un.org/womenwatch/daw/ beijing/platform/poverty.htm

U.S. Department of Agriculture. (n.d.). Rural income, poverty, and welfare: Rural poverty. Retrieved from http://www.ers.usda. gov/briefing/incomepovertywelfare/ruralpoverty/

Westgate, C. E. (1996). Spiritual wellness and depression. Journal of Counseling \& Development, 75, 26-35.

Wilson, S. M., \& Peterson, G. W. (1993). The process of educational and occupational attainment of adolescent females from lowincome, rural families. Journal of Marriage and the Family, 55, $158-176$.

Witmer, J. M., Sweeney, T. J., \& Myers, J. E. (1998). The Wheel of Wellness. Greensboro, NC: Author.

World Health Organization. (2001). The world health report 2001: Mental health: New understanding, new hope. Retrieved from http://www.who.int/whr/2001/en/

Zientek, L. R., \& Thompson, B. (2006). Commonality analysis: Partitioning variance to facilitate better understanding of data. Journal of Early Intervention, 28, 299-307. 